\title{
Taking stock of changes in quality assurance in Portuguese higher education between 2007 and 2015
}

\author{
Cristina Sin
}

CENTRO DE INVESTIGAÇÃO DE POLITICAS DO ENSINO SUPERIOR (CIPES)

csinfacipes.up.pt

ORCID: 0000-0001-6039-8194

\section{Orlanda Tavares}

CENTRO DE INVESTIGAC̦ÃO DE POLITICAS DO ENSINO SUPERIOR (CIPES)

orlandalacipes.up.pt

ORCID: 0000-0002-8750-2032

\section{Alberto Amaral}

AGÊNCIA DE AVALIAÇÃO E ACREDITAÇÃO DO ENSINO SUPERIOR (A3ES)

alberto.amaraldिa3es.pt

ORCID: 0000-0003-4263-3765

Received: 03/01/2017

Accepted: 24/03/2017

\begin{abstract}
This article documents the changes that occurred in Portugal after the adoption of the new higher education quality assurance framework in 2007. The most obvious results of the new higher education evaluation and accreditation agency's actions can be observed primarily at the level of teaching-program provision. Accreditation activities resulted in a 40\% reduction in the supply of the courses on offer between 2009 and 2015 (Sin et al., 2016). This reduction was felt mainly in private institutions, which confirms that substandard programmes were more common in the private sector. Another consequence was that institutions started to take a more formal and systematic approach to quality by implementing internal quality assurance systems. These systems were driven by a logic of accountability rather than by genuine self-reflection aiming to engage all those involved and which would have led to improvement. Therefore, it appears that most academics perceive internal quality assurance to have had negative effects on teaching and learning, mainly because of increased bureaucracy, while the positive effects are still perceived as being relatively modest.
\end{abstract}

Keywords: quality assurance in higher education, accreditation, internal quality assurance, accountability, teaching improvement.

Corresponding author: Cristina Sin, Centro de Investigação de Politicas do Ensino Superior (CIPES). R $1^{\circ}$ Dezembro 399 , 4450-227 Matosinhos, Portugal.

Suggested citation: Sin, C., Tavares, O. and Amaral, A. (2017). Taking stock of changes in quality assurance in Portuguese higher education between 2007 and 2015. Debats. Journal on Culture, Power and Society, 2, 163-173. doi: http://dx.doi.org/10.28939/ iam.debats-en.2017-13 


\section{INTRODUCTION}

Quality assurance in higher education became very important in Europe with the implementation of the so-called Bologna Process, far-reaching higher education reform designed to both create the European Higher Education Area (EHEA) and to aid the convergence of national higher education systems in Europe. The "promotion of European cooperation with respect to quality assurance in order to develop comparable criteria and methodologies" was one of the six initial lines of action proposed by the Bologna Declaration (1999). It was understood as an "absolutely essential element in the construction of the European Higher Education Area" (Haug, 2003, p. 230). European Standards and Guidelines (ESG) for Quality Assurance in the EHEA (Standards and Guidelines for Quality Assurance in the European Higher Education Area, 2015) were developed as a reference point to guide the work of European institutions and quality assurance agencies in the implementation of quality assurance and accreditation policies (ENQA, 2005). Portugal, in a similar way to many other European countries, used Bologna as a frame of reference for reforming its higher education system, and reorganised its quality assurance systems according to the ESG proposals.

Based on research carried out over the last four years (Cardoso et al., 2015a, 2015b; Sin et al., 2016; Tavares et al., 2016a, 2016b), this article documents the changes that occurred in Portugal after the adoption of the new higher education quality assurance framework in 2007. First, we explain the context that determined the evolution of quality assurance in Portugal, paying special attention to the most recent developments, since 2007, in the quality system restructuring. Next, we analyse the main outcomes resulting from the activities of the accreditation quality assurance agency, from its creation, and look at the strengths and weaknesses of these internal quality assurance systems in relation to their implementation in Portuguese institutions. Following on from this, we consider Portuguese academics' perceptions of teaching and learning improvements resulting from the implementation of these internal quality assurance systems. Finally, we present our conclusions regarding the changes that have occurred in Portugal so far, the impact of the new quality framework, and routes for future development in this area.

\section{REFORMS RELATED TO QUALITY ASSURANCE IN PORTUGAL}

To understand the evolution of quality assurance in Portugal, we must first briefly describe the transformations the Portuguese higher education system has undergone over the past four decades. The system consists of public and private institutions, universities, and polytechnic colleges. ${ }^{1}$ Although participation in higher education was low before the 1974 revolution and was a privilege of the elite (Amaral and Teixeira, 2000), access to higher education grew enormously after the political and social changes brought about by that revolution. The speed of the higher education expansion-initially elite, then massive, and finally universal (Trow, 1974)—especially between 1985 and 2000, made Portugal 'exceptional' compared to other countries in Western Europe where participation grew more gradually (Neave and Amaral, 2012). As a result, by the end of the 1990s, participation in higher education reached $50 \%$ in Portugal (Amaral and Magalhães, 2007).

Growth in participation was sustained mainly through a substantial private sector expansion (from about 20,000 students in 1987 to almost 100,000 in 1995). The government stimulated this strategy because it allowed an increase in enrolments without

\footnotetext{
1 Currently, the public sector comprises 12 universities, an open university, and an independent ISCTE (Instituto Superior de Trabajo y Ciencias Empresariales-Higher Institute of Labour and Business Sciences) institute. There are also 15 polytechnic institutes and, in addition, some universities include some polytechnics as part of their structure. Most universities and public polytechnics were founded in the 1970s and 1980s. The private sector currently comprises about 80 institutions (including the Catholic University), most of which were created in the 1980s and 1990s to facilitate system expansion and access for the growing number of students.
} 
requiring the investment of public funds (Amaral and Teixeira, 2000). But, little attention was paid to the quality of education during this expansion, a problem also observed in other contexts where the demand for higher education dramatically increased in a short period of time, for example in China (Cao and Li, 2014), Eastern Europe (Galbraith, 2003), and Chile (Espinoza and González, 2013). Given that the generation of profit is of the utmost importance for the private sector, institutions aimed to maximise enrolment by investing more in infrastructure than in teaching, learning, or staffing, which affected overall academic quality (Espinoza and González, 2013, Cao and Li, 2014, Sin et al., 2016). In Portugal, for example, there is still a significant difference in the academic qualifications of teaching staff employed at public and private institutions: in $2005,72.6 \%$ of teachers had a doctorate in public institutions compared to $55.3 \%$ in private institutions. Even so, the percentage of professors with a doctorate in private institutions is relatively high now compared to the situation ten years ago (Sin et al., 2016). It should also be noted that the offer of cheap or popular education courses and the low level of research carried out at private Portuguese institutions (because these primarily focus on education) also contributed to discrediting the private sector (Teixeira and Amaral 2007; Teixeira, 2012). Furthermore, lower entry grades are required for applicants who want to study at private institutions, and the association between the level of these students and the quality of institutions further damages the image of private institutions in society (Tavares, 2013).

Portugal, like other countries (Cao and Li, 2014, Espinoza and González, 2013), resorted to quality evaluation practices to try to resolve these problems. In the 1990s, a system was established that entrusted institutions with guaranteeing their own quality, which was coordinated via their representative body, the Portuguese Universities Foundation. Initially, the system only covered public universities, but in the year 2000 it was extended to public polytechnics and the private sector, while it simultaneously began to operate under the Consejo Nacional para la Evaluación de la Educación Superior (CNAVES-the National Council for the Evaluation of Higher Education). Access to higher education had already massively increased because of the governmental policies prioritising it at the expense of the overall quality of the system (Amaral, 2008; Tavares et al., 2016a). However, the evaluation structure coordinated by CNAVES was unable to preserve the quality of education because no consequences were defined for poor evaluation outcomes. In other words, although many low-quality degree courses existed, no decisions were ever taken to close any of them. In addition, the decision regarding accreditation belonged to the government rather than CNAVES. A new law enacted in 2003 (Law 1/2003) aimed to specify the consequences of the evaluation, but unfortunately complementary supportive legislation was never passed alongside it.

Portugal's commitment to the Bologna process gave a new impetus to higher education reform, including that of quality assurance. In 2006, at the request of the Portuguese government, the European Association for Quality Assurance in Higher Education (ENQA) reviewed the national quality assurance system and made a series of recommendations. These included using the ESG as the main reference structure, increasing the independence and transparency of the system, expanding its internationalisation, promoting student participation, and ensuring that the scheme produces effective results (closure of programs with low-quality teaching). Thus, the government approved a new law that completely reformed the system (Decree-Law 369/2007). The Agency for Evaluation and Accreditation of Higher Education (A3ES) was created under this new legal framework, as a private foundation to operate independently from the government and higher education institutions (Amaral et al., 2013), and was given a mandate to accredit the quality of institutions and their teaching programs. A3ES's activity began in 2009 when it started to accredit teaching, and has recently begun to certify the internal quality assurance systems of institutions. In addition, it will soon present its official processes for institutional accreditation. 


\section{ACCREDITATION RESULTS}

Given the poorly controlled growth in the supply of higher education programs in Portugal since the 1990s, teaching accreditation was the first step required to 'clean' the system of courses which did not meet the expected quality standards. In addition, after creating new teaching programs according to the Bologna process guidelines, accreditation was seen as a valid process for ensuring that curricular renewal was complying with legal requirements and thus, avoiding erosion of the quality of academic practices. Institutions are now only authorised to offer existing or new courses which are accredited. As such, the Directorate-General for Higher Education, a body of the ministry which supervises higher education, receives information about A3ES's decisions and maintains a register of accredited programs. It is illegal to offer non-accredited programs and doing so is subject to penalisation by the Education Inspectorate.

This new quality evaluation system, whose role in the initial phase was mainly teaching-course accreditation, has had visible consequences. There have been significant improvements in the quality of teaching staff, although there is still considerable room for improvement (see Sin et al., 2016). The criteria for teaching staff quality are stipulated in Decree-Law 74/2006 (modified by Decree-Law 115/2013 and Decree-Law 63/2016). For example, $60 \%$ of undergraduate teaching staff must be employed full time by the institution, a percentage that rises to $75 \%$ for postgraduate programs. In addition, different criteria are established for universities and polytechnics for the proportion of their teachers who must have a doctorate degree. In universities, at least $50 \%$ of the teaching staff in undergraduate programs must have a doctorate, a proportion which rises to $60 \%$ for master's programs, and 100\% for doctoral programs, according to Decree-Law 74/2006. For polytechnics, this proportion is $50 \%$ for all degree-levels, but in addition to staff with doctorates, these institutions can also contract 'specialists'. The latter are teachers who hold a higher-education degree and who have ten years' professional experience and a very relevant résumé. In addition, they must be recognised by a panel of internal and external institution members comprising both academics and professionals in the area in question.

When the new agency began operating in 2009 there were 5,262 degree-programs on offer that had to be evaluated and accredited (Sin et al., 2016). First, A3ES invited institutions to submit digital documentation for all their programs in operation and to demonstrate compliance with the clearly-defined quality criteria. A total of 4,379 programs delivered this information, while the remaining 883 programs were withdrawn by the institutions themselves. Because exhaustive evaluation for so many programs was impracticable, A3ES began a preliminary accreditation exercise that evaluated the programs presented according to three predefined indicators: the faculty staff and their degree-level qualifications, research activity in the field at the institution, and the number of students enrolled in the course. This phase resulted in 3,930 accreditations, 335 programs that were voluntarily discontinued by the institutions, and 114 courses that were denied accreditation. Thus, in the first two years, 1,332 programs from the initial 5,26 disappeared, corresponding to $25 \%$ of the courses that were on offer in 2009 (Sin et al., 2016). In the academic year 2011/12, after this preliminary accreditation period, the agency began a 5 -year periodic accreditation cycle, approving programs from specific disciplinary areas each year. Because of accreditation commission visits in the first four years of this regular cycle, 190 programs were denied certification (representing little more than $8 \%$ of the total), while another $19.9 \%$ were withdrawn by the institutions themselves (Sin et al., 2016).

The distribution of programs by sector (public vs. private), institution type (university vs. polytechnic), and education levels are shown in Table 1. Concerning the distinction between public and private institutions, most programs with preliminary accreditation are in public institutions (2,308 programs, representing $80 \%$ of the courses available). According to national statistics, in the academic year $2009 / 10$, the public sector offered $71.2 \%$ of the available degree programs compared to $28.8 \%$ in the private sector. This meant 
that the public sector obtained higher rates of preliminary accreditations. In contrast, the percentage of discontinued programs was higher in the private sector (28\% compared to $17.9 \%$ in the public sector). The difference between the sectors was even more noticeable for denied accreditations ( $2.3 \%$ in the public sector compared to $35.6 \%$ in the private sector). Therefore, these data suggest that quality deficiencies were more common in the more poorly controlled private sector.

There were no major differences between the universities and polytechnics regarding non-accredited and discontinued degree programs (Table 1). This suggests that the quality of the courses on offer was primarily determined by the sector type rather than the institution type and its respective mission.

Most of the preliminary accreditations were granted to master's degree programs (Table 1), reflecting the explosion in the range of these programs on offer after the Bologna reforms. Decree-Law 74/2006, which required the structure of degree courses to be adjusted to the Bologna proposals (up until 2009/10), also meant that pre-Bologna undergraduate degrees could only be replaced by post-Bologna undergraduate degrees, while this limitation did not apply to master's degree programs. Therefore, there was massive growth in the range and availability of master's degrees, while their quality was not always simultaneously monitored, thus explaining why these courses also later had the highest voluntary discontinuation rate (24.4\%). Doctoral programs $(9.8 \%)$, followed by master's degrees $(9.0 \%)$, had the highest percentage of denied accreditations. Law 62/2007 established that, in order to maintain their status as a university, institutions had to offer at least three doctoral programs. This meant that some private universities had to create doctoral programs, with less regard for quality in some cases. Moreover, postgraduate education is subject to more demanding conditions in terms of research activity and teacher qualifications.

Table 1: The distribution of teaching programs in the first four years of regular accreditation, by sector, institution type, and education level: preliminarily accreditations, discontinued courses, submissions for regular accreditation, and courses denied accreditation

\begin{tabular}{|c|c|c|c|c|c|c|c|}
\hline & & $\begin{array}{l}\text { PRELIMINARILY } \\
\text { ACCREDITATIONS }\end{array}$ & DISCONTINUED & $\%$ & $\begin{array}{l}\text { REGULAR } \\
\text { ACCREDITATION } \\
\text { SUBMISSIONS }\end{array}$ & $\begin{array}{l}\text { ACCREDITED } \\
\text { DENIED }\end{array}$ & $\%$ \\
\hline \multirow[t]{3}{*}{ Sector } & Public & 2308 & 412 & $17.9 \%$ & 1896 & 43 & $2.3 \%$ \\
\hline & Private & 574 & 161 & $28.0 \%$ & 413 & 147 & $35.6 \%$ \\
\hline & Total & 2882 & 573 & $19.9 \%$ & 2309 & 190 & $8.2 \%$ \\
\hline \multirow[t]{3}{*}{ Type } & University & 1980 & 380 & $19.2 \%$ & 1600 & 132 & $8.3 \%$ \\
\hline & Polytechnic & 902 & 193 & $21.4 \%$ & 709 & 58 & $8.2 \%$ \\
\hline & Total & 2882 & 573 & $19.9 \%$ & 2309 & 190 & $8.2 \%$ \\
\hline \multirow[t]{4}{*}{ Level } & $\begin{array}{l}\text { Bachelor's } \\
\text { degree }\end{array}$ & 1134 & 181 & $16.0 \%$ & 953 & 65 & $6.8 \%$ \\
\hline & $\begin{array}{l}\text { Master's } \\
\text { degree }\end{array}$ & 1391 & 340 & $24.4 \%$ & 1051 & 95 & $9.0 \%$ \\
\hline & $\begin{array}{l}\text { Doctorate } \\
\text { degree }\end{array}$ & 357 & 52 & $14.6 \%$ & 305 & 30 & $9.8 \%$ \\
\hline & Total & 2882 & 573 & $19.9 \%$ & 2309 & 190 & $8.2 \%$ \\
\hline
\end{tabular}


During the period under review, which includes the preliminary accreditation phase and the first four years of the regular accreditation cycle, $40 \%$ of the courses initially offered $(2,095$ programs from 5,262) were withdrawn (Sin et al., 2016). This occurred either because A3ES denied accreditation (304 programs) or because of institutional decisions to withdraw or discontinue the remaining degree courses, possibly because the institutions in question did not believe these courses would have met the agency's quality standards. Some programs may also have been discontinued for other reasons, such as reorganisation of educational provision as a result of the Bologna process reforms, or because there were insufficient numbers of student enrolments. At the same time, some 2,100 new programs were submitted for A3ES accreditation during the same period, of which, about 1,300 were accredited and started to operate. In July 2015, a total of around 4,500 degree-courses were on offer (Sin et al., 2016).

A qualitative analysis of the reports available on the process of legal degree accreditation (Sin et al., 2016) - the discipline with the highest percentage of denied accreditations-revealed common factors that triggered rejection. These reasons were usually related to insufficient numbers of teachers with full-time contracts, teaching staff without academic qualifications and with poor research activity track-records, unclear or vaguely-defined program identities, and teaching, learning, and evaluation failures (for example, curricular inconsistencies or lack of rigor). These problems are similar to those affecting the Portuguese private education sector in general (Sin et al., 2016).

These data provide evidence that the Portuguese higher education system 'cleaning' process was a success. The voluntary withdrawal of a large number of programs suggests that higher-education institutions have become more aware of quality requirements. Portugal is currently completing the first phase of its quality assurance program, which is dominated by teaching accreditation. Because A3ES has already started internal quality assurance system certification, the country has entered a second quality assurance phase which is more focused on promoting awareness of quality among institutions (for a description of the different phases in quality assurance evolution, see Jeliazkova and Westerhejiden, 2007).

\section{CERTIFICATION OF INTERNAL QUALITY ASSURANCE SYSTEMS}

As mentioned above, reorganisation of the quality assurance system in Portugal was based on the guidelines formulated by the Bologna process. For example, when it defined its procedures, A3ES consulted the ESGs. Portuguese institutions appear to have interpreted the European and, especially, the national reference guidelines very similarly within their specific contexts, thus leading to very similar internal quality assurance systems. Contrary to the initial expectations, each institution's assimilation of these guidelines did not result in a wide range of structural/administrative components specific to the institutions' own particular characteristics. Their margin for interpretation and freedom to design systems according to their own situations and organisational culture seems to have been limited-most probably by the evaluation model proposed by A3ES (Cardoso et al., 2015a). Therefore, despite the Agency's insistence that its references to quality assurance are not prescriptive, they clearly still determine institutional behaviour; this is likely because institutions are aiming to limit their risks, and perhaps also because they lack a tradition of dealing with quality in a formal way and they may have limited capacities to innovate in this sense.

A qualitative analysis of the strengths and weaknesses of the implementation of internal quality assurance systems was recently carried out based on internal and external evaluation reports (Tavares et al., 2016a). This research assessed whether these strengths and weaknesses were associated with procedural and structural issues or if they were associated with cultural changes manifesting themselves as values and attitudes. Because A3ES wanted to promote a culture of improvement when it introduced its systems for certifying internal 
quality assurance, this research sought to ascertain whether institutions were committed to continuous improvement rather than only accountability itself. The work also aimed to understand the culture(s) of quality at the institutions it analysed.

The strengths and weaknesses identified were mainly associated with the organisation of quality assurance and information management systems, that is, with formal structures and procedures rather than with quality in a transformational sense (Harvey and Newton, 2007). In other words, aspects such as the professional development of teachers or the participation of those who might be implicated or involved in quality assurance, received less attention than formal aspects, suggesting that procedures were prioritised over improvements themselves. It seems that institutions' motivation to implement internal quality systems and request their certification was mainly determined by their desire to avoid complex accreditation processes in the future. While A3ES intended to encourage improvement, it appears that accountability has remained a more pressing concern.

The institutions analysed seem to have quality cultures that vary between reactive and responsive (Harvey and Stensaker, 2008). A reactive culture is characterised by being strongly influenced by external rules and is motivated by compliance and accountability imposed by and built around external factors. This raises doubts about the possible positive results of the quality evaluations it performs. In a reactive culture, there is little or no sense of individual responsibility for quality because it is delegated to a specific unit (quality office). For academics, it amounts to a compliance exercise. The intensity of external quality rules is also strong in responsive cultures. Although external imperatives are important motivations for these institutions, they also take advantage of this opportunity to plan internal improvement programs looking towards the future, but without losing sight of accountability and compliance. However, this culture fails to link institutional activities related to guaranteeing quality to academics' daily activities. Analysis of external reports seems to indicate that polytechnics are weaker in terms of stakeholder participation and more concerned about procedures rather than improvement in itself. Thus, this research suggests that while polytechnics seem to be more reactive, universities appear to be more responsive.

This analysis was limited to twelve institutions who were pioneers in the implementation and certification of their internal quality assurance systems. Because only a limited number of Portuguese institutions have so far requested certification, it is not yet possible to draw general conclusions about Portuguese institutions as a whole.

\section{PERCEPTIONS OF HOW QUALITY ASSURANCE REFORMS} HAVE IMPROVED TEACHING AND LEARNING

The extensive quality assurance reforms in higher education, which has hitherto manifested itself in the processes of teaching accreditation and the implementation of internal quality assurance systems, has not yet had the desired impact in terms of improvements in teaching and learning.

A survey of teachers working in Portuguese higher education institutions found that the main impact of implementing internal quality assurance systems is a greater demand for them to dedicate time to non-academic tasks which, in fact, is detrimental to teaching and learning (Tavares et al., 2016b). This bureaucracy has been consensually identified in the literature as an unwanted side effect of quality assurance which diverts academics' time and energy away from teaching and research (Cartwright, 2007; Newton, 2002; Harvey and Newton, 2007). However, academics did acknowledge that internal quality assurance has contributed to a greater awareness of the problems related to teaching quality, as confirmed by some previous studies (Brennan and Shah, 2000, Baldwin, 1997), showing that this guarantee translates into greater attention to teaching.

On a less positive note, to date, this increased awareness does not seem to have led to real appreciable improvements or to a wider platform for innovation 
and experimentation in teaching and learning. A previously identified weakness (Cardoso et al., 2015a) was the near non-existence of pedagogical training in institutions, a situation which academics report has not improved after the implementation of internal quality assurance systems; this could at least partly explain the lack of tangible or visible results in teaching and learning practices. In fact, pedagogical training is the only issue related to teaching and learning that academics clearly feel has not improved. In other words, internal guarantees of quality have not led to improved pedagogical teacher training. In the context of the recent emphasis on teachers' pedagogical development in European higher education policies (Sin, 2015), which was reinforced in the revised version of the ESG (Standards and Guidelines for Quality Assurance in the European Higher Education Area, 2015), pedagogical training is an area in which institutions could invest, especially given its importance to the quality of teaching and learning. Therefore, these results once again indicate that internal quality guarantees in Portuguese institutions, appear to be more strongly associated with an increase in bureaucracy and formalisms and not with substantial improvements in teaching and learning. However, this research also found that teachers consider their participation in the development of internal quality assurance systems, and the use of information collected by the institution, to have had a positive impact on teaching and learning (Tavares et al., 2016b).

Although no significant difference has been observed between teachers in universities and polytechnics, the public-private variable is clearly noteworthy. Private sector academics consider the impact that internal quality assurance has had on various aspects related to the improvement of teaching and learning to have been much higher than those in the public sector do. This includes a greater awareness of the importance of teaching quality, improved focus on innovation and experimentation in teaching and learning, more pedagogical teacher training, and improvement of the quality of teaching and learning in general. Because private institutions in Portugal have traditionally placed less importance on quality, especially during the years of rapid expansion (see above), they have received an additional incentive to improve teaching and learning by establishing stricter and more demanding quality systems than they have had in the past. This may also explain why academics from private institutions have more positive perceptions of the impact that internal quality assurance has had on teaching and learning.

This impact represents a poorly researched area (Harvey and Williams, 2010) that has generated diverse results. In this context, this paper provides useful empirical evidence about Portuguese academics' perception of these changes. The results suggest that there are a number of relevant topics that could be considered by higher education institutions to achieve their pedagogical improvement objectives; these include streamlining administrative processes and procedures to avoid overloading academics, investing in pedagogical training, formally or informally involving teachers in quality assurance to increase their commitment to quality (Horsburgh, 1998), and using the information collected to improve teaching and learning.

\section{CONCLUSION}

Transformations in higher education policy at the European level, stimulated mainly by the Bologna process, are also reflected in Portugal's reorganisation of its quality assurance system from 2007 onwards. The most visible change, and the one that has had the greatest impact on higher education institutions, was the creation of A3ES. The most evident results from this Agency's operations can be observed in the range and types of degree courses now on offer. Its accreditation activities led to a $40 \%$ reduction in the original range of available teaching programs, a reduction which was mainly felt in private institutions, confirming that substandard teaching was more common in this sector (Sin et al., 2016).

Another consequence of the creation of A3ES was a change in the way institutions approach quality assurance. Institutions became engaged with a more 
formal and systematic approach to quality, a practice that was once relatively uncommon. Institutions were encouraged to establish their own internal quality assurance systems based on several non-prescriptive guidelines developed by the Agency. However, most of the institutions that have already implemented internal quality assurance systems replicated these systems without necessarily adapting them to their specific objectives and contexts, thus, establishing very similar formal structures to each other (Tavares et al., 2016a). In addition, implementation of these internal systems was driven by a logic of accountability and compliance with A3ES guidelines rather than by genuine internal reflection involving all the interested parties and which could lead to improvement (Tavares et al., 2016a). This reveals a unilateral and underdeveloped view of quality, probably explained at least in part, by the initial phase of the internal quality assurance system implementation in institutions. In fact, the main issues identified in relation to the implementation of these structures are associated not with values and attitudes towards quality, but rather, with formal and organisational structures and procedures. Therefore, academics seem to perceive the main effect of internal quality assurance on teaching and learning as being negative, because it entails an increase in bureaucracy, while the positive effects are still perceived as being rather modest.

On the one hand, this bureaucratic burden is the consequence of the way institutions have interpreted the implementation. But, on the other hand, it is also the result of a complex accreditation process which was required to eliminate sub-par teaching programs from the system (Tavares et al., 2016b). In order to ease the burden of bureaucracy, quality assurance in Portugal is moving towards a new phase-institutional accreditation. This aims to implement a more flexible evaluation regime which, for institutions that have proven themselves able to manage their own quality, may include the evaluation of only a sample of the educational courses on offer along with an annual monitoring process based on a set of predetermined indicators.

\section{ACKNOWLEDGEMENTS}

This work was supported by the Foundation for Science and Technology (FCT—-the Fundação para a Ciência e a Tecnologia) in Portugal [XCL/IVC-PEC/0789/2012 and UID/CED/00757/2013].

\section{REFERENCES}

Amaral, A., and Magalhães, A. (2007). Market Competition, Public Good and Institutional Governance. Higher Education Management and Policy, 19(1), 1-14.

Amaral, A., and Teixeira, P. (2000). The Rise and Fall of the Private Sector in Portuguese Higher Education. Higher Education Policy, 13(3), 245-266.

Amaral, A., Rosa, M. J., and Fonseca, M. (2013). The Portuguese Case: Can Institutions Move to Quality Enhancement? In R. Land, and G. Gordon (ed.), Enhancing Quality in Higher Education. International Perspectives (p. 141-152). London: Routledge.

Amaral, A. (2008). A reforma do ensino superior português. In A. Amaral (ed.), Políticas de ensino superior. Quatro temas em debate (p. 17-37). Lisbon: Conselho Nacional de Educação.

Baldwin, G. (1997). Quality assurance in Australian higher education: The case of Monash University. Quality in Higher Education, 3(1), 51-61.

Brennan, J. and Shah, T. (2000). Quality assessment and institutional change: experiences from 14 countries. Higher Education, 40(3), 331-49. 
Cao, Y., and Li. X. (2014). Quality and Quality Assurance in Chinese Private Higher Education: A Multi-dimensional Analysis and a Proposed Framework. Quality Assurance in Education, 22(1), 65-87.

Cardoso, S., Tavares, O., and Sin, C. (2015a). The quality of teaching staff: higher education institutions' compliance with the European Standards and Guidelines for Quality Assurance — the case of Portugal. Educational Assessment, Evaluation and Accountability, 27(3), 205-222.

Cardoso, S., Videira, P., and Rosa, M. J. (2015b). On the road to regaining trust? The development of internal quality assurance systems in Portuguese Higher Education Institutions. Paper presented at CHER 28th Annual Conference, Lisbon, 7-9 September.

Cartwright, M. J. (2007). The rhetoric and reality of 'quality' in higher education: an investigation into staff perceptions of quality in post 1992 universities. Quality Assurance in Education, 15(3), 287-301.

Decree-law 369/2007, 5 November, of the Portuguese Government.

Decree-law 74/2006, 24 March, of the Portuguese Government.

Decree-law 115/2013, 7 August, of the Portuguese Government.

Decree-law 63/2016, 13 de September, of the Portuguese Government.

ENQA. (2005). ENQA Report on Standards and Guidelines for Quality Assurance in the European Higher Education Area. Brussels: ENQA.

Espinoza, Ó., and González, L. E. (2013). Accreditation in Higher Education in Chile: Results and Consequences. Quality Assurance in Education, 21(1), 20-38.

Galbraith, K. (2003). Towards Quality Private Higher Education in Central and Eastern Europe. Higher Education in Europe, 28(4), 539-558.

Harvey, L., and Newton, J. (2007). Transforming quality evaluation: moving on. In D. F. Westerheijden, B. Stensaker, and M. J. Rosa (ed.), Quality Assurance in Higher Education. Trends in Regulation. Translation and Transformation (p. 225-45). Dordrecht: Springer.

Harvey, L., and Stensaker, B. (2008). Quality Culture: Understandings, Boundaries and Linkages. European Journal of Education, 43(4), 427-442.

Harvey, L., and Williams, J. (2010). Fifteen Years of Quality in Higher Education: (Part Two). Quality in Higher Education, 16(2), 81-113.

Haug, G. (2003). Quality Assurance/Accreditation in the Emerging European Higher Education Area: a possible scenario for the future. European Journal of Education, 38(3), 229-241.

Horsburgh, M. (1998). Quality monitoring in two institutions: A comparison. Quality in Higher Education, 4(2), 115-135.

Jeliazkova, M., and Westerheijden, D. F. (2002). Systemic Adaptation to a Changing Environment: Towards a Next Generation of Quality Assurance Models. Higher Education, 44(3-4), 433-448.

Law 1/2003, 6 January, of the Portuguese Government. Regime Jurídico do Desenvolvimento e da Qualidade do Ensino Superior.

Neave, G., and Amaral, A. (2012). Introduction on Exceptionalism: The Nation, a Generation and Higher Education, Portugal 1974-2009. In G. Neave, and A. Amaral (ed.), Higher Education in Portugal 1974-2009 (p. 1-48). Dordrecht: Springer.

Newton, J. (2002). Views from below: academics coping with quality. Quality in higher education, 8(1), 39-61.

Sin, C. (2015). Teaching and learning: a journey from the margins to the core in European higher education policy. In A. Curaj, L. Matei, R. Pricopie, J. Salmi, and P. Scott (ed.), The European Higher Education Area: Between Critical Reflections and Future Policies (p. 333-350). Dordrecht: Springer.

Sin, C., Tavares, O., and Amaral, A. (2016). The impact of programme accreditation on Portuguese higher education provision. Assessment \& Evaluation in Higher Education, 1-12. doi: 10.1080/02602938.2016.1203860

Standards and Guidelines for Quality Assurance in the European Higher Education Area (ESG). (2015). Brussels: Belgium.

Tavares, O. (2013). Routes towards Portuguese higher education: students' preferred or feasible choices? Educational Research, 55(1), 99-110.

Tavares, O., Sin, C., and Amaral, A. (2016a). Internal quality assurance systems in Portugal: what their strengths and weaknesses reveal. Assessment \& Evaluation in Higher Education, 41(7), 1049-1064. 
Tavares, O., Sin, C., Amaral, A., and Videira, P. (2016b). Academics' perceptions of the impact of internal quality assurance on teaching and learning. Assessment \& Evaluation in Higher Education, 1-13. doi: 0.1080/02602938.2016.1262326

Teixeira, P. (2012). The Changing Public-Private Mix in Higher Education: Analysing Portugal's Apparent Exceptionalism. In G. Neave, i A. Amaral (ed.), Higher Education in Portugal 1974-2004: A Nation, a Generation (p. 307-328). Dordrecht: Springer.

Teixeira, P., i Amaral. A. (2007). Waiting for the Tide to Change? Strategies for Survival of Portuguese Private HEIs. Higher Education Quarterly, 61(2), 208-222.

Trow, M. (1974). Problems in the Transition from Elite to Mass Higher Education. In General Report on the Conference in Future Structures of Post-Secondary Education. Paris: Organisation for Economic Cooperation and Development.

\section{BIOGRAPHICAL NOTES}

Cristina Sin is a postdoctoral researcher at CIPES (Centro de Investigação de Políticas do Ensino Superior). She has a PhD in Educational Research from Lancaster University (UK). She previously worked at the Higher Education Academy (UK) on educational projects aimed at improving teaching and learning in higher education.

Orlanda Tavares is a researcher at CIPES and at A3ES. She has a doctorate in Education Sciences from the University of Porto (Portugal) and investigates issues related to quality assurance in higher education and higher education policies.

Alberto Amaral has a doctorate from Cambridge University, and is a researcher at CIPES and a professor at the University of Porto, where he was rector from 1985 to 1998. He is currently the chairman of the board of directors of the Portuguese Higher Education Evaluation and Accreditation Agency. 


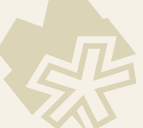

